\title{
Fertility Decline and Social Change: New Trends and Challenges
}

\author{
Bali Ram \\ Housing, Family and Social Statistics Division \\ Statistics Canada \\ Department of Sociology and Anthropology \\ Carleton University \\ Ottawa, Ontario, Canada
}

\section{Abstract}

This article presents an overview of recent fertility declines and their effects on social change in both industrialized and industrializing countries. The focus is primarily on the levels and age patterns of fertility, which influence social change through three major mechanisms, reductions in population growth, modifications in age structure, and changes in family structure. Some future prospects are also discussed, especially in the view of the viability of immigration as a solution to population stability, graying of the industrialized world, intergenerational support, and loneliness.

Key Words: below-replacement fertility, population decline, loneliness, intergenerational support 
Bali Ram

\section{Résumé}

Cet article présente un survol de la baisse récente de fécondité et de ses effets sur les changements sociaux dans les pays industrialisés et les pays en voie d'industrialisation. L'article porte principalement sur les niveaux de fécondité et la distribution de fécondité par âge, qui influent sur le changement social par trois mécanismes importants, soit la réduction de la croissance de la population, les modifications dans la structure par âge, ainsi que les changements à la structure familiale. Il est question de certaines perspectives d'avenir, particulièrement en ce qui a trait à la viabilité de l'immigration comme solution à la stabilité de la population, au vieillissement du monde industrialisé, au soutien intergénérationnel, et à la solitude.

Mots-clés : fécondité en-dessous du seuil de remplacement, diminution de la population, ,solitude, soutien intergénérationnel

\section{Introduction}

Ever since the publication of Malthus' An Essay on the Principle of Population in 1798, people have been writing books and articles about the social and economic effects of population growth. Following the principle of nature, Malthus prophesied that "the reproductive urge would push population beyond Nature's ability to provide subsistence. Population would expand in geometric fashion, but food, only arithmetically." Malthus' name has come to be synonymous with a pessimistic view of population, which received a major boost by a proliferation of neo-Malthusian writings on the negative consequences of population pressure in academic and popular literature. Early demographers and non-demographers alike echoed this view as a result of a rapid decline of mortality but rather slow or no declines in fertility in major parts of the world. Terms such as "population explosion", "vital revolution", and even more ideologically tainted "population bomb", were coined to describe the rapid growth of population.

The picture has changed since the 1970s, following fertility declines in industrialized countries, as well as in a number of less industrialized countries. As early as 1967, Bogue had predicted "the end of the population explosion", but that was largely ignored, perhaps because of his overemphasis on the role of the size, quality and spread of the family planning campaign on fertility reductions. However, in view of the sustained fertility declines in a majority of countries, including demographic giants such as China and India, there have been speculations in recent years about "population implosion," as Eberstadt (1997) labels it. 
Fertility Decline and Social Change: New Trends and Challenges

At the beginning of the first millennium, the population of the world stood at around 300 million. A thousand years later, the population size had changed little. Natural disasters, epidemics, and wars did not allow the population to grow. However, due to progress in medicine and improvement in life styles and health habits, and consequently, due to reductions in mortality - infant mortality in particular-the population exploded during the second millennium, reaching just over six billion by the year 2000 . During the past fifty years due to declines in fertility in a number of countries, the world population has been growing at a slower rate of $1.7 \%$ per year'. Over the next fifty years, according to the 'medium variant' projections ${ }^{2}$ of the United Nations (1999) the world population is expected to grow at a rate of $0.83 \%$ per year. Thus the world population will continue to grow in the foreseeable future, reaching nearly nine billion people by 2050 , but the growth rate will be reduced markedly, for example, at $0.38 \%$ between 2040 and 2050. The United Nations' projections also indicate that reductions in population growth are expected to occur in all regions of the world, with a number of countries in more developed regions experiencing a negative growth within the next two decades. These reductions will be largely due to the sustained below replacement level fertility in more developed regions and expected reductions in fertility in less developed regions.

In this paper, evidence is presented to suggest that recent fertility declines have either already brought or will bring in the future large-scale changes in the ways of thinking and behaviour of people, countries and governments. Some examples of such changes are: the introduction of pronatalist policies, the ease in the immigration of working-age foreign nationals, the modification in intergenerational support systems, and a critical look at ethnic equilibrium. These changes are affected by both levels and age patterns of fertility. These dimensions influence social change through several mechanisms, three of which are the focus of this paper: reductions in population growth, modifications in age structure, and changes in family structure.

\section{Fertility Trends}

\section{Global Fertility Decline and Convergence}

During the past half-century, especially during the latter part, most countries of the world have experienced a fertility decline. The world total fertility rate has dropped from about 5.0 births per woman in the early 1950s to 4.5 in the early 1970s and to less than 3.0 by the 1990s. Except for a few countries in Africa, fertility has been declining in every part of the world, depicting a convergence between world regions (Figure 1)

The world average conceals large differences across countries and regions. While some countries have been experiencing below-replacement level 


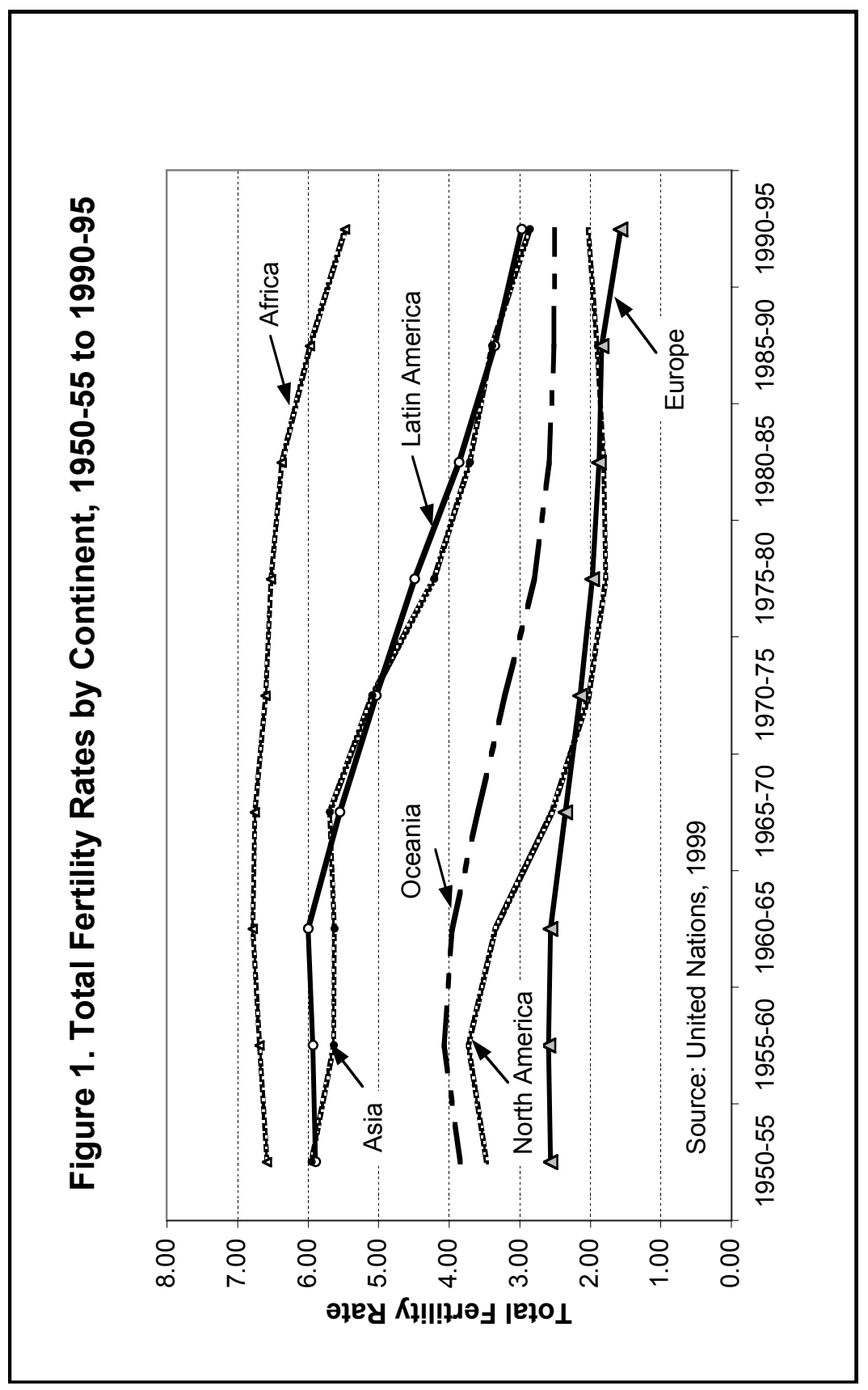


fertility ${ }^{3}$ since the mid-1970s or before, others had fertility levels above replacement until recently, but observed large reductions rather quickly. There is yet another group of countries where fertility levels are high, but have been declining at a moderate pace in recent years, whereas in others where fertility rates are much above (more than double) the replacement level, and the pace of decline is relatively slow. Only in a few countries (mostly in Africa) fertility rates are much above (more than three times) the replacement level and the decline did not begin until the early 1990s.

At present, almost all industrialized countries have a fertility level at or below replacement. A number of countries (e.g., Austria, Belgium, Denmark, France, Germany, Greece, Luxembourg, Netherlands, Russian Federation, Sweden, Switzerland, Ukraine, and U.K.) have been experiencing below replacement fertility for almost three decades, whereas almost half of them have reached a level as low as 1.5 births per woman. All of these countries are from Europe, although quite a few from other regions have joined the group rather rapidly. France, Sweden and West Germany, for instance, are frontrunners, with long histories of low fertility. Italy, Spain, Greece and Portugal entered the transition rather late, but experienced fertility declines at a very fast pace, surpassing all others and exhibiting total fertility rates below 1.5 today. Japan is the only country outside of Europe, which experienced an early fertility transition. The fertility decline in Japan began during the $1930 \mathrm{~s}$, but plunged to a spectacularly low level within less than a decade, reaching 2.0 by the end of 1950s (Kono, 1994). During the following fifteen years (1960-1975), the total fertility rate stabilized around two children, but then declined further to a level significantly below replacement (1.5 in 1990-95).

Several other Asian countries, most notably, Singapore, Hong Kong, Taiwan, and Republic of Korea (South Korea) were latecomers but joined the low fertility group rather quickly (Figure 2). Their fertility levels started to decline in the late 1950 s or 1960 s, but were reduced by more than half within less than two decades. Fertility levels of these countries have converged with the levels of the "pioneer countries", which have been experiencing low fertility for quite some time. The experiences of Indonesia, Sri Lanka, and Thailand, which have already reached total fertility levels below 3.0, are somewhat similar. China's experience is especially noteworthy. Up to 1970 , its fertility had been high, fluctuating around six births per woman, except during crisis periods. During the 1970s, China experienced an unprecedented fertility decline, and within a brief interval of just ten years, its total fertility rate was reduced to less than half, reaching 2.3 in 1980. With the announcement of the one-child policy in 1979, China's fertility level was further reduced to 1.8 in 1996. It is important to note that China's case is not typical of other less industrialized countries, because its fertility decline is primarily an outcome of the governmental effort to direct its population growth. In India - another demographic giant-which is a subcontinent in itself and represents much of the diversity of South Asia, fertility decline has been rather slow, despite its decades old national family 
planning programme. However, levels in some of its provinces (e.g., Goa, Kerala and Tamil Nadu) have already reached below the replacement level. In Bangladesh, despite its low economic development, fertility rate was halved within less than twenty years, from 6.7 in 1975-80 to 3.4 in 1990-95. Also, data from the World Fertility Survey (1975-76) and the Demographic and Health Survey (1993-94) indicate that the mean desired number of children in this country was reduced from 4.1 to 2.5 , one of the lowest in the developing world.

For a long time Latin America and the Caribbean in general fell into the high fertility zone. Over recent decades fertility rates in some smaller countries (e.g., Cuba, Barbados, Trinidad and Tobago, Puerto Rico) have reached replacement level, whereas in some larger ones (e.g., Brazil, Mexico, Argentina, Venezuela, and Colombia) declines have been marked. Africa as a whole still belongs to the group where either fertility has been stagnant or is declining slowly. Prominent among those where fertility has been stagnant (with a total fertility rate of 6 or more) include Angola, Burundi, Chad, Congo, Ethiopia, Guinea-Bissau, Liberia, Mali, Niger, Somalia, Uganda, Sierra Leone. However, recently major fertility declines have occurred in countries such as Botswana, Ghana, Kenya, South Africa, Swaziland, and Zimbabwe. In most countries of this region, the mean desired number of children among currently married women still remains high (e.g., 6.5 in Uganda, 6.8 in Cameroon and 8.2 in Niger). Although both the desired number of children and actual fertility have been reduced substantially in most countries, with Zimbabwe, Botswana, and Kenya leading the way, it is likely that high infant mortality and lack of education, especially among women, stand as major obstacles in fertility transition in this region.

The effect of high prevalence of HIV/AIDS on African fertility is not clear. It is generally known that sub-Saharan Africa has the highest adult prevalence of HIV $(8.8 \%$ in 2000$)$ in the world, with Botswana (36\%), Zimbabwe (25\%), Swaziland (25\%), Lesotho (24\%), Zambia (20\%), South Africa (20\%), Namibia (19\%), Malawi (16\%), and Mozambique (13\%) as the worst-affected countries (Ntozi, 2002). The impact of HIV/AIDS on fertility could be serious, since it is the women in reproductive age groups who are affected most. A review of the literature prepared by Ntozi (2002) suggests that HIV infection induces sterility, increases foetal mortality, decreases frequency of intercourse, and consequently reduces the pregnancy rate and raises levels of induced abortion. Studies conducted in the early and mid-1990s in Rwanda, Tanzania, Uganda, Zaire, and Zambia also conclude that the overall fertility of HIV-positive women is $25 \%-40 \%$ lower than that of HIV-negative women. However according to the United Nations (2002), the impact of the prevalence of HIV infection on the overall fertility is estimated to be less than $10 \%$. 


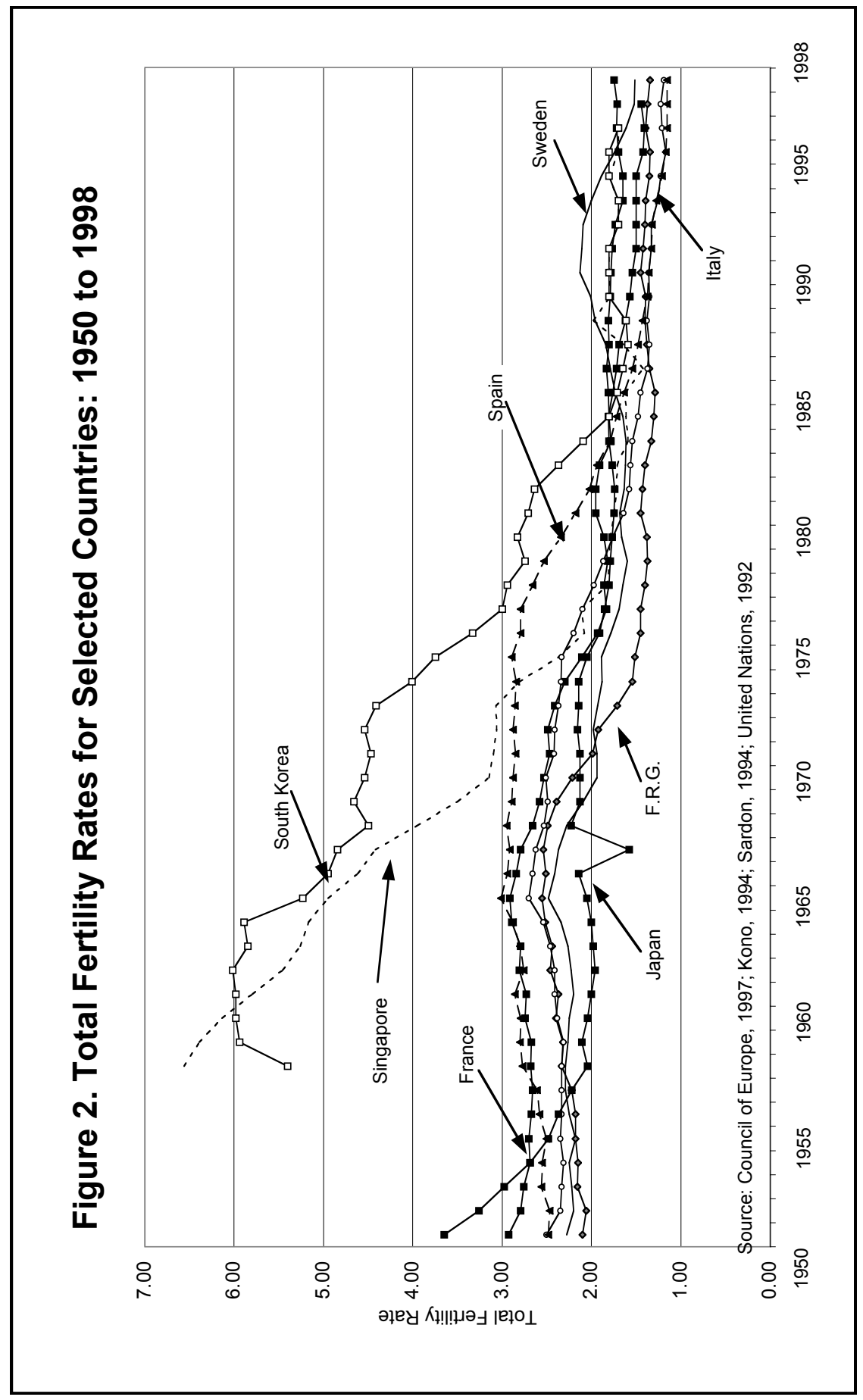




\section{Delayed Childbearing and Childlessness}

In recent years, increasing proportions of women in industrialized countries are not only having a smaller number of children but they are having them-especially the first ones-later in life. In most countries, the age of motherhood has been rising since the 1970s, although the largest increase has taken place in recent years. Within a brief interval of five years, the mean age of women at the birth of their first child in countries where reliable data are available, rose by about one year, reaching 26 years or beyond by the mid-1990s (Table 1). Studies show that the first-order birth rate which is generally a demographic phenomenon of women in their $20 \mathrm{~s}$, has been increasing among women over the age of 30, since the early $1970 \mathrm{~s}$ (Ram, 2000; Morgan, 1996). Delayed childbearing is largely a function of delayed marriage patterns, although many people who delay getting married - at least in the West - may be living common-law, and therefore, they are not necessarily less exposed to sexual unions. However, studies show that persons living in common-law unions are more likely to delay having children and not produce as many children as legally married couples, because they are not as certain about their conjugal status.

Although in recent years the age at first birth has increased in a number of developing countries, it still falls at the lower end of the reproductive life cycle. According to the Demographic and Health Surveys conducted between 1986 and 1994, the median age at first birth in countries involved varied between 18 and 23 years, with Sri Lanka being an outlier where the median age was 24 years (United Nations, 1998:56). In most countries, a large part of fertility decline occurred primarily due to the shift to a later age at marriage rather than delayed childbearing and declines in marital fertility. Marital fertility remains relatively high, especially among women below age 30 and early childbearing remains a norm in these countries.

Substantial delays in the initiation of motherhood have often been linked with ultimate childlessness (Morgan, 1991; 1996). Postponing childbearing until the mid-30s can have an adverse effect on the physiological potential of women to conceive. It is also likely that the longer a woman remains childless, the less inclined she will be to have a child. Either she gets involved in activities, which are incompatible with lifestyles involving children or she gets used to living alone. However, in most industrialized countries, the average age at first birth has increased markedly, but the incidence of childlessness has increased only modestly (Morgan, 1996). Japan is a classic example where women start childbearing at a much later age, but fewer remain permanently childless compared with women in the industrialized world. In Canada, the United States, and (West) Germany, which are at the forefront of increased acceptance of childlessness, the proportions of married women of recent birth cohorts (e.g., 1951-55), who had never born any children by the near-end of their reproductive lives are 
Fertility Decline and Social Change: New Trends and Challenges

no higher $(13.0 \%, 17.7 \%$, and $19.4 \%)$ than for women of a number of earlier cohorts (e.g., 1906-10 and 1911-15). In Europe, the proportion of women who regard childlessness as ideal basically remained unchanged between 1979 and 1989, around 4\%; only in a few countries such as West Germany and Belgium, was this proportion larger than $5 \%$ (Table 2).

In less industrialized countries, the extent of voluntary childlessness is even smaller. World Fertility Surveys and Demographic and Health Surveys indicate that almost all women in these countries would like to have a child. Between 1975-80 and 1986-94, the proportions of women who had never had any children by the end of their reproductive lives have either remained unchanged or have declined in most countries (United Nations, 1998:68). The incidence of childlessness was usually less than $5 \%$, which could well be the level of natural sterility in a population. Also, unlike in the West, there does not seem to be any rise in the proportions of couples who prefer to have only one child (United Nations, 1998).

\section{Future Prospects}

What then is to be expected in the future? In view of the sustained fertility declines, with levels as low as 1.5 children per woman in almost half of the countries in Europe, predicting substantially below the replacement fertility is not an unrealistic scenario for the industrialized world. According to the low scenario of the most recent projections from the United Nations (1999), during the next fifty years the total fertility level could vary between 1.4 and 1.5 for more developed regions and as low as 1.2 to 1.3 for Eastern and Southern Europe.

It is important to note, however, predicting fertility beyond 25 to 30 years-approximately the mean age of childbearing - involves too much uncertainty about the number of potential mothers in the population and their attitude toward family and children. Having witnessed the post-World War II turnaround of fertility, resulting in the well-known baby boom and then the following baby bust in a number of industrialized countries, it would be presumptuous to expect that the extraordinary low levels of fertility would continue into the future. Having reached a substantially low level, fertility in a number of countries has already been showing an upturn in recent years. Between the early 1980s and the early 1990s, the total fertility rate rose from 1.61 to 2.13 in Sweden, from 1.38 to 1.76 in Denmark, from 1.66 to 1.93 in Norway, from 1.63 to 1.85 in Finland, from 1.42 to 1.64 in Luxembourg, and from 1.76 to 1.84 in the U.K. (Sardon, 1994). It has been argued that lower fertility levels in most countries have resulted from the making up of the births couples had postponed earlier, and when further postponement of childbearing ceases, there will be an upturn in fertility rates (Bongaarts and Feeney, 1998). However, as Lesthaeghe and Willems (1999) show, period total fertility rates in most countries will 


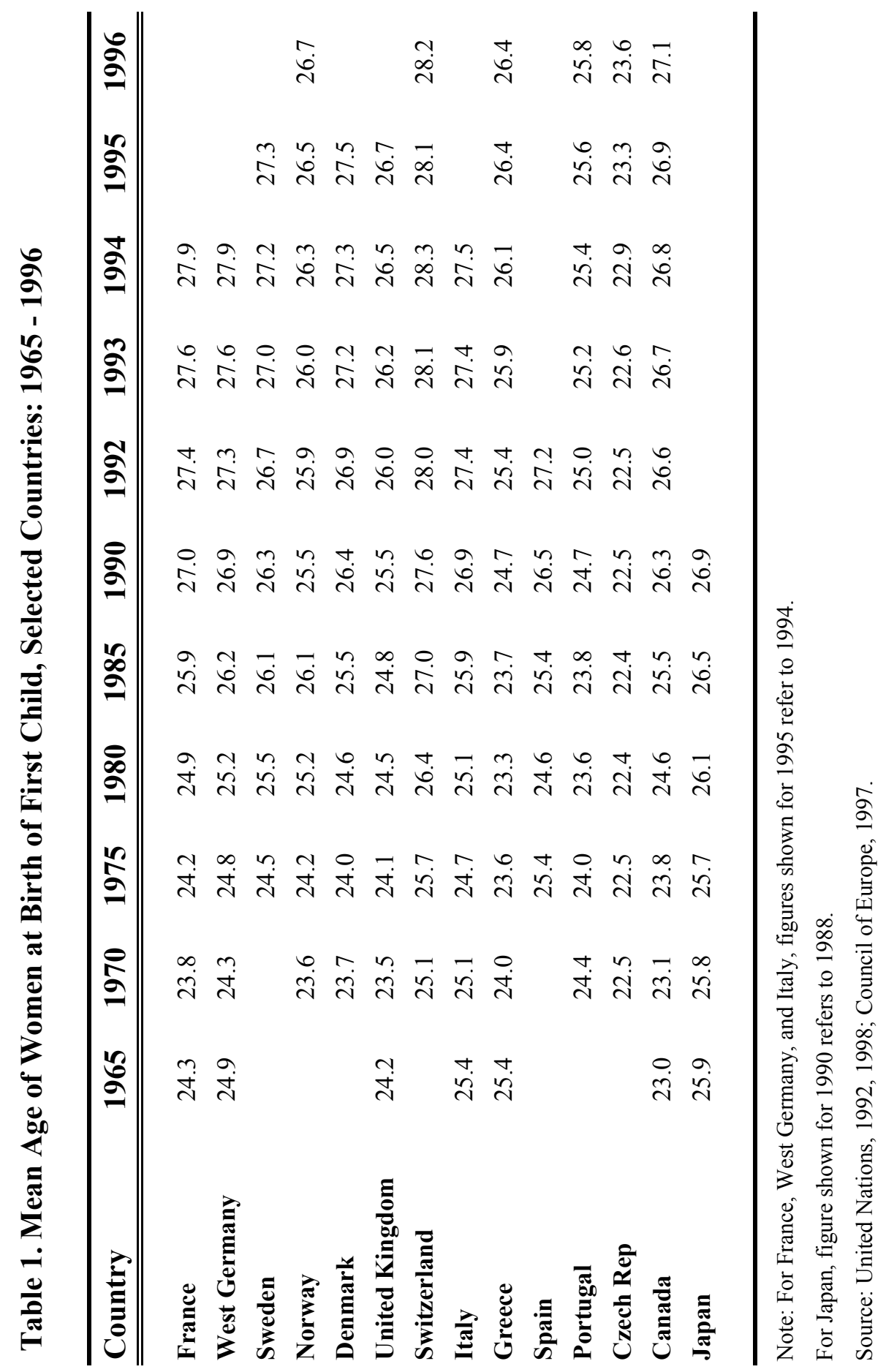




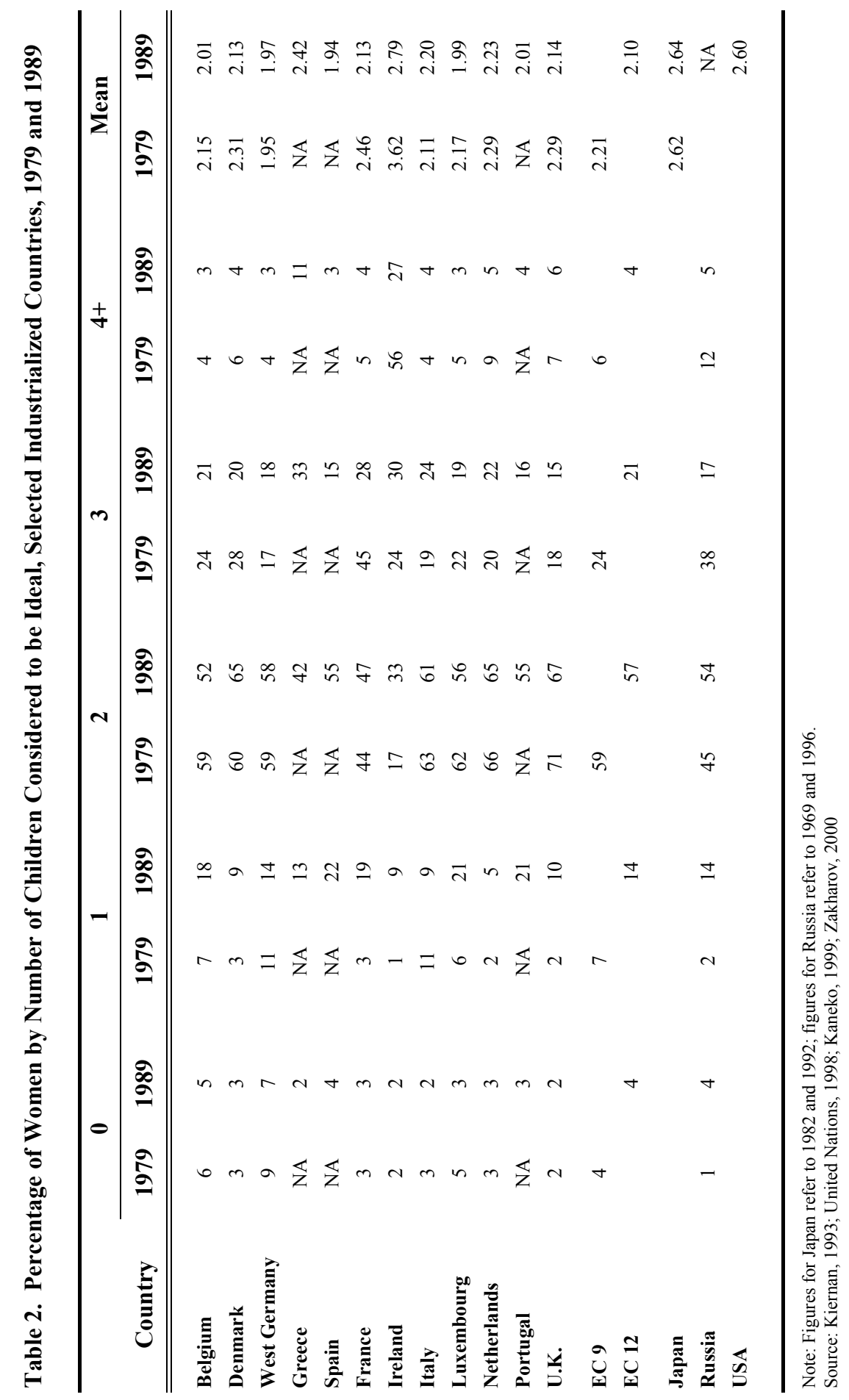


Free from the timing effects are the completed cohort fertility rates, which in recent years are not only considerably higher than the period total fertility rates, but have also been declining at a slower pace. Unlike the period total fertility rate, the completed cohort fertility rate in recent years has remained closer to, although still below, the replacement level. The completed cohort fertility rates have stabilized at around $1.9-2.1$ in a number of countries (e.g., France, Hungary, Norway, Sweden, Denmark, and United Kingdom), whereas they are still sliding in others (e.g., Spain, Italy, and Portugal).

The sub-replacement level fertility in industrialized countries is consistent with the existing norms about the ideal family size and the ultimate birth expectations. The ideal family size in most countries has not changed much over the years and remains at around two children per woman. Also, as the Fertility and Family Surveys project undertaken in the European community, the United States, and Canada around 1990 indicate, the average ultimate family size expected ranges between 1.9 and 2.4 births per woman (Table 3). Interestingly, there is a marked similarity between women aged 40 to 44 , most of whom may have completed their family size, women aged 30 to 34, most of whom have had at least one child, and those 20 to 24 years, most of whom are yet to begin their families. If couples stick to their expectations about having two children (which is not only a contentious hypothesis in itself, but also usually presents an overestimate of fertility behaviour), fertility is not likely to rise much from the present level.

Predicting the replacement level fertility in less industrialized countries is even more presumptuous. High-fertility norms are rational responses to conditions of high mortality and kinship systems in a peasant agricultural economy. This is all the more conspicuous in highly patriarchal societies (such as India, China, and South Korea) where the preference for a son is strong or couples desire a balanced number of sons and daughters. Thus couples may end up having, on the average, at least two children.

\section{Reductions in Population Growth}

\section{Prospects for Population Decline}

The most obvious result of fertility decline is the decrease in population growth, which could eventually lead to potential decline. Because of their momentum, populations in most low-fertility countries are still growing. However, declines can be expected within the next few years, according to population projections prepared by the United Nations (1999). The population of Europe has been growing by less than 1.0 percent per annum for the past fifty years. If fertility remains below the replacement level, it could start declining within the next five years, exhibiting a negative growth rate of $0.15 \%$ per annum during the first quarter of this century and $0.45 \%$ per annum during the second quarter. These projections also suggest that the 
Table 3

Average Number of Children Ultimately Expected by Women, Selected Industrialized Countries for Specified Years

\begin{tabular}{|c|c|c|c|c|c|}
\hline Country & Survey Year & $20-24$ & 30-34 & $40-44$ & Mean \\
\hline Austria & 1996 & 2.0 & 2.0 & 2.7 & 2.2 \\
\hline Canada & 1990 & 2.3 & 2.1 & 2.0 & 2.1 \\
\hline Finland & 1989 & NA & 2.2 & NA & 2.2 \\
\hline France & 1994 & 2.1 & 2.3 & 2.3 & 2.3 \\
\hline Germany & 1992 & 1.8 & 2.0 & NA & 1.9 \\
\hline Hungary & 1993 & 2.1 & 2.1 & 2.0 & 2.1 \\
\hline Italy & $1995-96$ & 2.1 & 2.1 & 2.0 & 2.1 \\
\hline Latvia & 1995 & 2.1 & 2.3 & 2.0 & 2.1 \\
\hline Lithuania & 1995 & 2.0 & 2.1 & 1.9 & 2.0 \\
\hline Netherlands & 1993 & 2.3 & 2.1 & 2.0 & 2.1 \\
\hline Norway & 1988 & 2.5 & 2.2 & 2.3 & 2.4 \\
\hline Poland & 1991 & 1.7 & 2.3 & 2.3 & 2.2 \\
\hline Slovenia & 1995 & 2.3 & 2.3 & 2.1 & 2.2 \\
\hline Spain & 1995 & 2.2 & 2.2 & 2.3 & 2.2 \\
\hline Sweden & 1992 & 2.4 & 2.5 & 2.2 & 2.4 \\
\hline United States & 1992 & 2.1 & 2.1 & NA & 2.1 \\
\hline
\end{tabular}

Source: Bachu, 1993; Bongaarts, 1999; United Nations, Various years. 
population of North America is expected to grow at a rate of $0.30 \%$ between 2025 and 2050. Even the growth rates in Asia and Latin America could be as low as $0.44 \%$ and $0.60 \%$, respectively during that period.

The prospect of population decline could be more serious for certain subnational groups. The case of French Canada is worth mentioning in this context. The prospect for population decline in the province of Quebec, which is largely inhabited by a Francophone population, has given rise to political resurgence in the province. Quebec's fertility level used to be the highest in Canada, but since the mid-1950s and especially after its so-called "quiet revolution" in the 1960s, it has become the lowest (Lachapelle, 1990). In spite of a number of pronatalist measures introduced by the provincial governments, its fertility has remained low, hovering around 1.5-1.6 births per woman for about two decades. Many demographers and politicians fear that if the low fertility is sustained in the future, its population will start declining by 2016, which means a threat of survival to a culture which is so unique in North America (McNeill, 1998:335; Teitelbaum and Winter, 1998:176).

\section{Dilemma of Immigration Solution}

With sustained fertility declines in industrialized countries, the relative importance of natural increase and immigration as components of population growth have shown a dramatic shift in recent years. Europe presents a classic example of this scenario, where international migration accounted for $30 \%$ of the total population increase during $1985-90$, but $88 \%$ ten years later in

1990-95 (United Nations, 1998: 15). Italy shifted from a country of high fertility and emigration to a country of low fertility and large immigration (primarily return migration). In the Federal Republic of Germany, natural increase and international migration each accounted for about half of the total population increase in 1960; in 1990 international migration accounted for virtually all of it. Canada, which in the industrialized world, stands only next to Australia in terms of its large immigrant population (17\% in 1996), registered a similar trend. In spite of its volatile economic conditions and unfavourable public opinions, Canada has been receiving a substantial number of immigrants to maintain its population growth at about one percent. Between 1961-66, international migration accounted for just $15 \%$ of the population growth; the share quickly rose to $30 \%$ in $1966-71$ and to $38 \%$ in 1971-76. In recent years, the contribution of immigration has been around $50 \%$ of the population growth.

Although from time to time many countries have introduced pronatalist policies to increase population growth, they have not been successful in the long run. The experiences of European countries suggest that pronatalist 
measures such as family allowances, financially compensated maternity leaves, shorter and flexible working hours for women with young children, and the like have a small, but only temporary effect on fertility (McIntosh, 1981; United Nations, 1992:72-73). Studies show that these incentives are either not enough to cover the additional cost of a child, or they are ineffective in stimulating fertility (Keyfitz, 1986).

Increased immigration has often been suggested as a viable means of offsetting the tendency for a low-fertility population to shrink (Espenshade, 1986:259), although intellectuals and popular opinions have not always favoured this option. According to a most recent compilation of global population policies by the United Nations (1999), lower population growth does not seem to be a grave concern to most governments; most view their current levels of population growth to be satisfactory and do not see a need for intervention to modify growth. Also, most governments want to maintain immigration, while others including Denmark, U.K., Austria, France, Germany, Switzerland, Greece, and Portugal want to reduce immigration. Only a few governments see the need of increased immigration as a means of achieving their demographic stability.

The findings of Prinz and Lutz's (1993) simulation for twenty large member States of the Council of Europe, are highly suggestive of the increased need of immigration for stabilizing population growth. They showed that with a total fertility rate of 1.3 births per woman (to be reached by 2015), a low rise in life expectancy and no immigration, their total population size would be reduced from 450 million in 1990 to only 340 million in 2050. As shown in Table 4, under this extreme scenario, the population size of countries such as Austria, Belgium, Bulgaria, Germany, Italy, and Hungary would be reduced by about $30 \%$ over a sixty-year period. Interestingly, even if fertility were to remain at 1.7 births per woman and net immigration were to be constant, at half a million, the population of a number of countries would either decline or would barely increase.

Using Statistics Canada's model and borrowing assumptions for the 1998based population projections, similar simulations were performed for Canada. ${ }^{4}$ Four scenarios were prepared. The first scenario assumes a constant total fertility rate at 1.5 births per woman throughout the projection period (1998 - 2051), an immigration of 210,000 per year during that period, and a slightly rising volume of emigration from 64,000 in 1998 to 75,000 in 2051 . The remaining three scenarios assume the net international migration to be absent during the projection period, while assuming varied fertility rates. In one case, the total fertility is assumed to remain constant at 1.5 , whereas in the other it is assumed to increase linearly to 1.8 in 2051 ; in the last scenario the fertility rate is assumed to decline linearly to 1.3 in 2051. In all these four scenarios, between 1998 and 2051 the life expectancy at birth is assumed to increase from 76 years in 1998 to 80 years in 2051 for males and from 81 years to 84 years for females. Results presented in Table 5 clearly show that unless Canada receives a substantial amount of 
immigration, its population will ultimately decline. If the total fertility rate remained constant at 1.5 births per woman during the projection period, and there was a net annual international migration in the tune of about 150,000, the population is likely to rise from 30.3 million today to 36.6 million in 2041 and start declining thereafter. However, if Canada had to experience a zero net migration, its population could start declining as early as 2031 , and could be reduced to just 25.8 million by 2051 . According to the extreme scenario with declining fertility and zero net migration, the population could be reduced further to 24.2 million in 2051. During this period, even if the total fertility rate were to rise to 1.8 , the population in 2031 could be lower than what it is today and by 2051 it could be reduced to 28.7 million.

Generally, large-scale immigration is not viewed "as a politically viable response to declining population" in industrialized countries (Teitelbaum and Winter, 1985:150). One of the major reasons for this is the fact that most immigrants in these countries originate from high fertility countries, located primarily in non-western regions. European countries are less likely to contribute to migration because they themselves are experiencing low fertility and declining population growth. Italy presents a classic example,

which used to be a high-emigration country, but it is facing its own population stagnation because of sustained low fertility; it is either getting immigrants from other countries or getting their migrants back. Canada, the United States, and Australia, which are largely inhabited by immigrant populations born in Europe, have been experiencing a decline in the European share of new admissions in recent years, whereas the share of immigrants originating from developing regions, particularly from Asia has substantially increased. Between 1975-79 and 1990-94, for instance, the proportion of immigrant admissions of Asian origin rose from $38 \%$ to $42 \%$ in the United States, from $32 \%$ to $55 \%$ in Canada, and from $33 \%$ to $51 \%$ in Australia.

In most receiving countries, there has been anxiety and hostility toward immigrants of non-European origin, especially because they bring with them a culture alien to the native people. In a 1993 Canadian poll conducted by Decima Research, $70 \%$ of the respondents believed that immigrants should adopt the Canadian ways of life rather than preserving or promoting their own cultural identities. In a Decima Research poll conducted in 1998, 50\% of Canadians supported a five-year moratorium on immigration. According to the Leger Marketing Survey conducted in 2002, 54\% of Canadians believed that Canada accepted too many immigrants. In Germany, there is a fear that if ethnic differentials in fertility were to remain unchanged, with German fertility far below replacement and Turkish fertility far above, the country would become predominantly Turkish in the not too distant future (McNeill, 1998: 332). Japan which faces a possible population decline within the next decade, remains xenophobic (Martin 1991:528), with 
Table 4

Population Size (in millions) for Twenty European Countries, 1990 and 2050

\begin{tabular}{|c|c|c|c|c|c|}
\hline \multirow[b]{2}{*}{ Country } & \multirow{2}{*}{$\begin{array}{c}\text { Population in } \\
1990\end{array}$} & \multicolumn{2}{|c|}{ Projected Population in 2050} & \multicolumn{2}{|c|}{ Percentage Change } \\
\hline & & Scenario 0 & Scenario 1 & Scenario 0 & Scenario 1 \\
\hline All Countries & 448.9 & 467.7 & 342.1 & 4.2 & -23.8 \\
\hline Austria & 7.6 & 7.6 & 5.4 & 0.0 & -28.9 \\
\hline Belgium & 9.9 & 9.7 & 7.1 & -2.0 & -28.3 \\
\hline Bulgaria & 9.0 & 8.0 & 6.3 & -11.1 & -30.0 \\
\hline Czechoslovakia & 15.7 & 15.8 & 12.5 & 0.6 & -20.4 \\
\hline Denmark & 5.1 & 5.1 & 3.7 & 0.0 & -27.5 \\
\hline Finland & 5.0 & 5.1 & 3.8 & 2.0 & -24.0 \\
\hline France & 56.7 & 65.2 & 47.6 & 15.0 & -16.0 \\
\hline Germany & 78.0 & 78.8 & 53.8 & 1.0 & -31.0 \\
\hline Greece & 10.2 & 10.5 & 7.5 & 2.9 & -26.5 \\
\hline Hungary & 10.6 & 9.0 & 7.0 & -15.1 & -34.0 \\
\hline Iceland & 3.7 & 5.2 & 4.0 & 40.5 & 8.1 \\
\hline Italy & 57.7 & 55.9 & 40.4 & -3.1 & -30.0 \\
\hline Netherlands & 14.9 & 16.4 & 11.7 & 10.1 & -21.5 \\
\hline Norway & 4.2 & 4.8 & 3.5 & 14.3 & -16.7 \\
\hline Poland & 38.4 & 41.3 & 32.8 & 7.6 & -14.6 \\
\hline Portugal & 9.9 & 11.6 & 8.4 & 17.2 & -15.2 \\
\hline Spain & 39.3 & 39.4 & 29.6 & 0.3 & -24.7 \\
\hline Sweden & 8.5 & 9.4 & 6.7 & 10.6 & -21.2 \\
\hline Switzerland & 6.6 & 7.4 & 4.9 & 12.1 & -25.8 \\
\hline U.K. & 57.3 & 61.3 & 45.4 & 7.0 & -20.8 \\
\hline
\end{tabular}

Note: Scenario ' 0 ' assumes a total fertility rate of 1.7 to be reached in year 2015 ; an increase in the life expectancy

by 2 years per decade until it reaches 83.5 years for males and 89.0 years for females; and 0.5 million immigrants annually to be reached in year 2000. Scenario ' 1 ' assumes a total fertility rate of 1.3 to be reached in year 2015; an increase in the life expectancy by 2 years per decade until it reaches 77.0 years for males and 83.0 years for females; and zero immigration

Source: Prinz and Lutz (1993) 


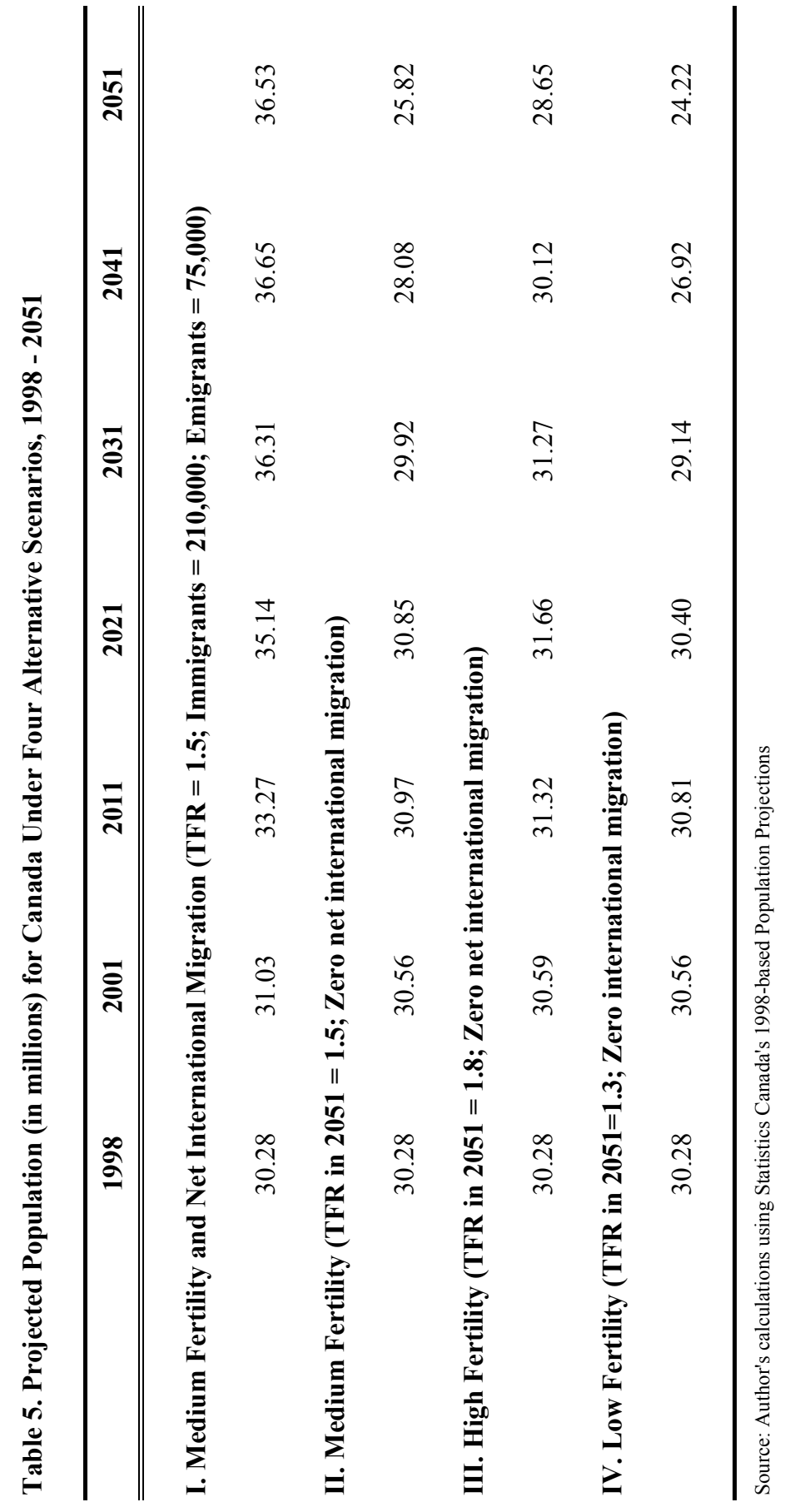


Fertility Decline and Social Change: New Trends and Challenges

negligible immigration. In Singapore, one of the lowest fertility countries in the East, the government has been enthusiastic about increasing immigration, but that has caused concerns among Malays and Indians, who form a minority. In the late 1980s, Singapore's decision to grant permanent residency status to some 100,000 people from Hong Kong within a short duration was interpreted as a move to increase the Chinese majority (Martin, 1991).

Anxiety and hostility toward immigration from non-western countries is also associated with a high degree of residential concentration of ethnic minorities in a few large urban centres. Because of various historical, cultural and economic factors, members of certain ethnic and immigrant groups, despite economic pushes at the places where they initially settled and economic pulls from other areas, tend to congregate to a few large metropolitan areas, which are heavily populated by their ethnic predecessors. In most receiving countries, there have been, from time to time, hostile expressions in the form of racial slurs and outbreaks of violence against these communities. Some well-known examples of such hostility include those against Turks in Germany, Algerians in France, Pakistanis and West Indians in Great Britain, and (East) Indians and Somalis in Canada.

\section{Changes in Age Structure}

Changes in fertility patterns are clearly reflected in the age distribution of population. The impact of current fertility declines will begin to have an impact on the reductions in the number of new admissions in primary schools about five years from now, on new entrants to the labour force about 18 to 20 years later, and so on. In 1950 , about $27.0 \%$ of the population in the industrialized world was below age 15; this was reduced to $18.2 \%$ in 2000 . As a consequence of sustained fertility declines, this proportion could be reduced to just $15.2 \%$ in 2050 . The corresponding proportion in Europe is expected to be reached much earlier, probably within the next five years. Low-fertility countries will also see marked reductions in the working-age population. Europe's population between the age group 15 to 64 , for instance, could decline from $67.8 \%$ now to $58.0 \%$ in 2050 . These trends imply that populations in low-fertility countries are aging, which are bound to exert large effects not only on that segment of the population, but on the overall society.

\section{Graying of the Industrialized World}

It is well established that in its initial stages population aging results primarily from fertility decline, although at later stages mortality reductions at older ages play an equally or more important role. Aging is not a new 
phenomenon in countries where fertility has been below the replacement level for some time. According to certain observers, it has reached an alarming stage, especially due to the extension of life expectancy among the elderly. As Peterson (1999: 42) asserts, "the graying of the developed world's population ... may actually do more to reshape our collective future" than even the proliferation of nuclear, biological, and chemical weapons, deadly super viruses, extreme climate change, and the violent ethnic explosions. Thus Peterson predicts that global aging will become the transcendental political and economic issue of the 21 st century and calls for a global solution.

All major regions of the world except Africa are growing older. Between 1965 and 1995, the median age of the world's population increased by 3.3 years, from 22.1 years to 25.4 years; in North America, the increase was 6.2 years, from 28.1 to 34.3 years. In Europe, which has led the aging world, the median age rose further from 30.9 to 36.1 during the same period. There is a clear relationship between low fertility and the intensity of aging; in countries which are among the world's "oldest", fertility rates have been significantly below the replacement level for quite some time. However, since recent fertility declines have been relatively gradual in these countries, the aging process has slowed down. In Germany, for instance, the median age rose from 34.4 years in 1965 to 38.4 years in 1995; in France, from 32.7 to 36.1 years; and in Sweden, from 36.2 to 38.9 years. However, the aging process has been accelerated in countries which experienced large fertility declines in a much shorter time span. Thus between 1965 and 1995, the median age rose from 27.3 to 39.7 years in Japan, from 32.1 to 37.7 years in Greece, and from 30.1 to 35.9 years in Spain. It is important to note, however, that even if fertility were to increase moderately, the aging process is not likely to be modified significantly in view of the large effects of mortality declines among older persons in recent years (Martin, 1989). A simulation performed on Canadian data revealed that fertility would have to increase from less than two births to four or five births per woman over the next twenty-five years, in order to cancel out the aging of population (George, Nault, and Romaniuc, 1991). In view of the increasing proportions of the elderly in the industrialized world living into their $80 \mathrm{~s}$ and $90 \mathrm{~s}$, the process of aging is expected to intensify in the future. The extremes are expected to occur in several European countries, with Italy, Greece, and Spain taking the lead position, where within the next fifty years, the median age could rise beyond 50 years and about one-third of the population could be 65 years and over.

Following rapid fertility declines, many less industrialized countries are moving closer to industrialized countries in terms of population aging. The most dramatic changes have occurred in Eastern Asia, especially Singapore and Hong Kong, where the median age jumped from less than 20 years in 1965 to beyond 30 years in 1995. China, Thailand, North Korea, South Korea, and Sri Lanka are also fast approaching these countries, although because their fertility declines are so recent, their aging process is still at a 
Fertility Decline and Social Change: New Trends and Challenges

very early stage. This acceleration of the aging process in these countries could "require qualitatively different responses from those observed in Western countries" (Jones, 1993:275).

In an aging population, the number of older persons increases at a faster pace than the number of persons in the working-age groups, which in turn results in a rise in the so-called "old-age dependency burden." Currently, Europe is at the forefront in this direction, with 4.6 persons in the potentially working-age group (15-64) for every potential retiree (persons 65 years and over). By 2050, this ratio is expected to be reduced to just 2 to 1 in Europe, and even lower in countries with extremely low fertility, such as Spain (1.3), Italy (1.5), Greece (1.6), and Japan (1.7). This implies that a smaller segment of the population would have to bear the burden of a large elderly population, in terms of the provision of social security, health facilities, transportation, housing, and the like. However, as Preston (1984) illustrated in his presidential address to the Population Association of America, this does not necessarily bring about adverse effects on the well-being of the elderly, because the savings accrued from having fewer children has been diverted to the welfare of older people. He illustrated that in the United States, the older population has in fact benefited from the redirection of the saving accrued from fewer children to the welfare of the elderly. Preston showed that between 1960 and 1982 the absolute number of children under 15 years shrunk by $7 \%$, while the number of older people over age 65 grew by $54 \%$, but contrary to what one would expect, these demographic changes operated in favour of the elderly and against the well-being of children. The proportion of children living in poverty rose from $16 \%$ to $23 \%$, while the proportion of the elderly living in poverty declined from $24 \%$ to $15 \%$.

These trends are bound to profoundly influence the social fabrics of the industrialized world, although much depends on the socio-economic conditions of the elderly themselves. For example, it is not certain what social security provisions are going to be available to them, how financially well-off they are going to be, how much further life expectancy of older people may rise, and how much of it will be in a healthy and active state. Equally uncertain are the impacts of medical and technological advances in the areas of genetics, cancer vaccines, and the like (Wilmoth, 1998).

\section{Intergenerational Support}

While the trend toward the rise in the proportion of the population that is 'oldest old' is unmistakable, the rise in the proportion of 'young elderly' is equally certain in the coming years. The longer life span has increased the probability of the existence of multigenerational households, which by implication means that potential supporters, usually those in the 45-54 age group will be "sandwiched" between the responsibilities for their own lateborn-although fewer-children and those of their elderly parents and perhaps grandparents. Two factors have reinforced this pattern. First, there 
has been an increase in the labour force participation of married women - the traditional care providers. Second, because of the increased years of schooling, children are staying longer with their parents before getting married or entering in the labour force.

The 'young elderly' parents are not going to be relieved from the support burden in the near future. Because of their smaller number of children, they will not be able to receive adequate support when they get older, but they will have to provide support to their 'oldest old' parents. In 1950, for every elderly aged 65-79, there were 2.18 persons aged 45-54 (potential supporters) at the world level (Table 6). This so-called "generational support ratio" declined to 1.63 by the year 1990 . By 2050 , that ratio could dwindle down to just 1.02 . This pattern is likely to be more pronounced in regions, which have experienced large declines in fertility and old-age mortality. In Europe, for instance, where the generational support ratio has been hovering around 1.20 over the past three decades, it is expected to drop rapidly to 0.82 by 2030 and 0.64 by 2050 . Patterns are equally discernible in the case of the "two older generation support ratios", which show the availability of the potential support for the oldest old. It is possible that many older people in industrialized countries are financially well-off independently or because of social security provisions available to them from the state, and are in a healthy condition. However, the traditional emotional support which older people receive from family members, children, grandchildren and other relatives could be missing. Moreover, people who provide support to the elderly are getting old themselves. Western societies will have to face the challenge of the increased loneliness of the oldest-old, most of whom will be elderly widows.

In most low-fertility countries in the non-western region, the situation is not that gloomy, especially in light of the fact that fertility declines and therefore the aging process are more recent. Moreover in many agricultural societies, Asia in particular, the family is the main source of economic and social support to the elderly, who generally live and work with their children. In South Korea which has experienced large fertility declines in recent years, more than two-thirds of the elderly population are dependent on their family members for most of their living cost, while less than onefifth earn incomes through their work (Lee and Palloni, 1992). Even in Japan the proportion of older persons co-residing with their children is still higher (65\% compared to $4 \%$ in Denmark), and a substantial majority wants to be cared for by their family members and finds it best for older and younger generations to live together (Martin, 1989; U.N., 1994: 3-4). In the process of demographic transitions of the 1960s and 1970s, these countries experienced large declines in infant mortality, while fertility remained high. As a consequence, the current generation of older persons has more surviving children than earlier generations. Although in view of the current low fertility, the number of children available to take care of their parents will be smaller in the future, the impact will be moderate with respect to the crucial aspect of support represented by co-residence. In Thailand, for 
instance, as Knodel, Chayovan, and Siriboon (1992) show, most elderly Thai parents will have at least two children available to them because the proportion of elderly parents who are likely to be childless $(6 \%)$, and those with only one child $(8 \%)$ will remain small in the next few decades.

Table 6

Generational Support Ratios

World Total and Europe, 1950-2050

\begin{tabular}{llccc}
\hline & \multicolumn{2}{c}{ 45-54/65-79 } & \multicolumn{2}{c}{$\mathbf{6 5 - 6 9 / 8 0 +}$} \\
Year & World & Europe & World & Europe \\
\hline $\mathbf{1 9 5 0}$ & 2.18 & 1.68 & 3.38 & 2.83 \\
$\mathbf{1 9 6 0}$ & 1.95 & 1.68 & 3.55 & 2.47 \\
$\mathbf{1 9 7 0}$ & 1.75 & 1.18 & 3.10 & 2.53 \\
$\mathbf{1 9 8 0}$ & 1.71 & 1.21 & 2.83 & 2.08 \\
$\mathbf{1 9 9 0}$ & 1.63 & 1.18 & 2.30 & 1.58 \\
$\mathbf{2 0 0 0}$ & 1.71 & 1.15 & 2.18 & 1.55 \\
$\mathbf{2 0 1 0}$ & 1.83 & 1.21 & 1.74 & 1.07 \\
$\mathbf{2 0 2 0}$ & 1.62 & 1.02 & 1.98 & 1.23 \\
$\mathbf{2 0 3 0}$ & 1.27 & 0.82 & 1.86 & 1.18 \\
$\mathbf{2 0 4 0}$ & 1.14 & 0.74 & 1.47 & 0.87 \\
$\mathbf{2 0 5 0}$ & 1.02 & 0.64 & 1.18 & 0.75 \\
\hline
\end{tabular}

Source: Computed from U.N. (1999) 


\section{Family Structure}

Fertility declines clearly mean reductions in the number of children, and consequently an increase in the proportions of smaller families. In the industrialized world, delayed childbearing coupled with the fact that most women do not wish to have a larger family size, has given rise to a proportion of births that belong to the first-order. In the 1960s, for instance, only a few member countries in the Council of Europe (e.g., Finland, Germany, Switzerland, Greece, and Hungary) had more than 40\% first-order births; by the 1990s, almost all countries (except Ireland) had exceeded that level. This implies that increasing proportions of children are being brought up without any brothers and sisters. This raises a number of questions concerning the personality make-up of tomorrow's children, and psychological atmosphere of the family and society. Is the West moving toward a society of selfish achievers and hyperactive people because children with few or no siblings can maximize resources, but have not been adequately taught to share with others and to have patience? Or, is society headed toward a golden age in which small family size has allowed members the advantages of sibship without the economic sacrifices of large families?

The one-child family is rare in developing countries, although with its onechild policy China is in a unique position. A one-child limit would imply that fewer than half of all couples will have a surviving son, which could result in the break of over $50 \%$ of the descent lines. In view of the fact that most Chinese couples would like to have at least one son, this limit would also lead to a heavily imbalanced sex ratio and consequently to gender inequality, marriage squeeze, and even physical abuse against first-born daughters and their mothers, as well as infanticide and abortions (Bongaarts and Greenhalgh, 1985:595-596).

Fertility decline has also been linked to the rise in the status of women, especially in terms of their access to higher education and increased participation in paid employment. In the West, it has freed women to enter and remain in the labour force. Moreover, children are no more an obstacle to women's labour force participation as they once used to be. In the United States and Canada, for example, the participation rate for all women increased over the last several decades, with faster increase among married women with younger children. In the mid-1990s, almost $70 \%$ of the wives with some children were in the labour force, both in Canada and the United States. In recent years, there is little difference between women with some children at home and those with children under age six. It is hard to imagine that there is going to be any marked reversal from this trend as women, who have enjoyed the benefits of working, would probably not like to be confined to familial activities in the future. 
By now it has been established that the increased labour force participation encourages women to keep their fertility level low, and low fertility allows them to participate in the labour force, thereby generating a self-regulating mechanism. In this process, children are usually born late when couples are at the peak of their career. It is likely that many career-oriented couples cannot afford to spend much time with their children in their formative years. Although couples may be able to buy child care services, books, televisions, computers, and other material resources, the lack of their involvement in their children's early education could contribute to a less than healthy development of a generation (Carnegie Corporation, 1996).

\section{Conclusion}

Over the past several decades, fertility has declined almost everywhere in the world except in a few African countries. However, there are marked variations between countries in terms of the pace of decline, while some low-fertility countries have been showing signs of stabilization. Two dominant themes emerge from the analysis of this global transition. First, parenthood remains an essential element in the lives of most people, although increasing proportions of them desire, and are having, a smaller number of children. It is highly likely that on average fertility would not be reduced below one child per couple in industrialized, low-mortality and less patriarchal societies, whereas it would be reduced to around the replacement level in less industrialized, high mortality, and highly patriarchal societies. In the coming years, these changes are likely to lead most people toward greater loneliness than ever before. In industrialized countries, an increasing proportion of children will be brought up alone without any siblings. The loneliness of these children will get reinforced with the increased labour force participation of their mothers, many of whom are likely to be at the peak of their career during the formative years of their children. Apparently, this scenario does not apply to less industrialized countries where the twochild family is still prevalent and most mothers are still at home.

One's senior years in life are becoming even lonelier in industrialized countries, despite the fact that most people are entering into the empty nest stage somewhat later. However, the real solitude begins after the death of a spouse, and that has been intensifying, especially among women. Usually, the oldest old receive support from relatives who themselves are old and alone. The loneliness of the current generation of older people is not critical in less industrialized countries because of the availability of a large number of their surviving children.

Obviously, not much can be done to reduce social isolation, because we know that the forces behind social isolation are largely irreversible in nature, either because they are beyond the control of human beings and social institutions, or they are for the general welfare of individuals. It is 


\section{Bali Ram}

nevertheless useful for social scientists and policy makers to acknowledge the need for studies on the consequences of and the mechanisms to cope with the solitude and social isolation of children, parents and the elderly.

The other scenario which has resulted from fertility declines and which dominates the social fabrics of industrialized countries is the increased need for workers from high-fertility countries, originating primarily from nonwestern cultures. Industrialized countries will be competing among themselves to attract immigrants who could easily assimilate and integrate into the society and economy of the host country. Since they will bring with them an alien culture, most immigrant groups may have to face hostility from the native population. A major challenge facing low fertility countries will be how to stabilize their populations through immigration from high fertility countries, without antagonizing the native population.

\section{Acknowledgements:}

This is a slightly revised version of the paper presented at the International Sociological Association Research Council conference on "Social Transformation at the Turn of the Millennium: Sociological Theory and Contemporary Empirical Research", Université de Montréal, July 28 - 30, 2000. I would like to thank my colleagues at Statistics Canada, M.V. George, Réjean Lachapelle, Gilles Montigny, Ed Shin, and Ravi Verma and two referees for many helpful suggestions on an earlier draft. The opinions expressed in this paper are mine, and do not necessarily reflect the views of Statistics Canada.

\section{End Notes:}

1. This rate is based on the estimates of world population provided by the United Nations Demographic Yearbook, 1999 (p. 89). According to the United Nations, world population grew from 2,521 million in 1950 to 4,440 million in 1980 and to 6,055 million in 2000.

2. Unless otherwise stated, throughout this paper I use the medium population projections series released by the United Nations (1999) to illustrate future demographic patterns in various regions and countries.

3. Although the replacement level - the rate required to maintain a constant population - could vary from country to country depending on the proportion of women surviving to the childbearing age and the sex ratio at birth, I use a total fertility level of 2.1 as the replacement level.

4. Demography Division of Statistics Canada has prepared various scenarios for population projections for the 1998-2026 period. This paper has made a slight modification to its fertility assumption, in that, 
Fertility Decline and Social Change: New Trends and Challenges

the total fertility level has been assumed to change linearly from 1998 to 2051. Also, a zero net international migration level has been assumed for certain scenarios. The author is thankful to Dr. Ed Shin for his help in preparing these simulations.

\section{References:}

Bachu, Amara. 1993. Fertility of American Women: June 1992. Current Population Reports, P20-470. Washington, D.C.: U.S. Bureau of the Census.

Bogue, Donald J. 1967. "The end of the population explosion," The Public Interest. Spring.

Bongaarts, John and Griffith Feeney. 1998. "On the quantum and tempo of fertility," Population and Development Review 24: 271-291.

Bongaarts, John and Susan. Greenhalgh, 1985. "An alternative to the onechild policy in China," Population and Development Review 11: 585-617.

Carnegie Corporation. 1996. Years of Promise: A Comprehensive Learning Strategy for America's Children. New York: Carnegie Corporation.

Council of Europe. 1997. Recent Demographic Developments in Europe, 1997. Council of Europe Publishing, Belgium.

Eberstadt, Nicholas. 1997. "World population implosion?" The Public Interest 129: 3-22.

Espenshade, Thomas J. 1986. " Population dynamics with immigration and low fertility," Population and Development Review 12 (Supplement): 2048-261.

George, M. V., F. Nault, and A. Romaniuc. 1991. "Effects of fertility and international migration on changing age composition in Canada." Statistical Journal of the United Nations ECE 8: 13-24.

Golini, Antonio. 1998. "How low can fertility be? An empirical examination," Population and Development Review 24: 59-73.

Jones, Gavin W. 1993. "Consequences of rapid fertility decline for old-age security," in Richard Leete and Iqbal Alam, The Revolution in Asian Fertility: Dimensions, Causes, and Implications. Oxford: Clarendon Press. Pp. 273-295. 
Bali Ram

Kaneko, Ryuichi. 2000. " Below-replacement fertility in Japan: Trends, determinants and prospects," in Population Bulletin of the United Nations, Special Issue 40/41:266-291. Pp. 266-291.

Keyfitz, Nathan. 1986. "The family that does not reproduce itself," Population and Development Review 12 (Supplement): 139-154.

Kiernan, Kathleen. 1993. "The future of partnership and fertility," in Robert Cliquet (ed.) The Future of Europe's Population. Council of Europe, Population Studies, No. 26. Pp. 23-44.

Knodel, John, Napaporn Chayovan, and Siriwan Siriboon. 1992. "The impact of fertility decline on familial support for the elderly: An illustration from Thailand," Population and Development Review 18: 79-103.

Kono, Shigemi 1994. "Ageing and the family in the developed countries and areas of Asia: Continuities and transitions," in Ageing and the Family, New York: United Nations. Pp. 34-44.

Lachapelle, Réjean. 1990. "Changes in fertility among Canada's linguistic groups," in Craig McKie and Keith Thompson, Canadian Social Trends. Thompson Educational Publishing. Pp. 153-159.

Lee, Yean-Ju and Alberto Palloni. 1992. "Changes in the family status of elderly women in Korea," Demography 29: 69-92.

Lesthaeghe, Ron and Paul Willems. 1999. "Is low fertility a temporary phenomenon in the European Union?" Population and Development Review 25: 211-228.

Martin, Linda G. 1989. "The greying of Japan," Population Bulletin Population Reference Bureau, 44: 1-42.

Martin, Linda. 1991. "Population aging policies in East Asia and the United States," Science 251: 527-531.

McIntosh, C. Allison. 1981. "Low fertility and liberal democracy in Western Europe," Population and Development Review 7: 181-207.

McNeill, William H. 1998. "The politics of declining populations," in Paul Demeny and Geoffery McNicoll, The Earthscan Reader in Population and Development. London: Earthscan Publications. Pp. 329-338.

Morgan, S. Philip. 1991. "Late nineteenth- and early twentieth-century childlessness," American Journal of Sociology 97: 779-807. 
Fertility Decline and Social Change: New Trends and Challenges

Morgan, S. Philip. 1996. "Characteristic features of modern American fertility," Population and Development Review 22 (Supplement): 19-63.

Ntozi, James P. M. 2002. "Impact of HIV/AIDS on fertility in sub-Saharan Africa." Fourth Meeting of the Follow-up Committee on the Implementation of the DND and ICPD - PA, Yaounde, Cameroon, January 2002.

Peterson, Peter G. 1999. "Gray dawn: The global aging crisis," Foreign Affairs 78: 42-55.

Preston, Samuel H. 1984. "Children and the elderly: Divergent paths for America's dependants," Demography 21: 435-457.

Prinz, Christopher and Wolfgang Lutz. 1993. "Alternative demographic scenarios for 20 large member States of the Council of Europe, 19902050," in Robert Cliquet (ed.), The Future of Europe's Population. Council of Europe. Pp. 85-106.

Ram, Bali. 2000. "Current issues in family demography: Canadian examples," Canadian Studies in Population 27: 1-41.

Sardon, Jean Paul. 1994. Fecondité generale. L'institut National d'Etudes Demographiques.

Teitelbaum, Michael and Jay Winter. 1998. A Question of Numbers: High Migration, Low Fertility, and the Politics of National Identity. New York: Hill and Wang.

Teitelbaum, Michael and Jay Winter. 1985. The Fear of Population Decline. Orlando, Florida: Academic Press.

United Nations. 1992. Patterns of Fertility in Low-Fertility Settings. New York: United Nations.

United Nations. 1994. "Overview of recent research findings on population ageing and the family," in Ageing and the Family, New York: United Nations. Pp. 79-104.

United Nations. 1998. World Population Monitoring 1996. New York: United Nations.

United Nations. 1999. World Population Prospects: The 1998 Revision. New York: United Nations.

United Nations. 2002. "HIV/AIDS and fertility in sub-Saharan Africa: A review of the research literature." ESA/P/WP.174. 
Bali Ram

United Nations. Various years. Fertility and Family Surveys in Countries of the ECE Region: Standard Country Report. New York and Geneva: United Nations.

World Bank. 1995. World Tables. Washington, D.C.: World Bank.

Zakharov, Sergi V. 2000. "Fertility trends in Russia and the European newly independent states: Crisis or turning point?" in Population Bulletin of the United Nations, Special Issue 40/41:292-317 